\title{
Migration and Distribution of Graft-inoculated Jujube Witches'-broom Phytoplasma within a Cantharanthus roseus Plant
}

\author{
Sanghun Lee, Chul-eung Kim and Byeongjin Cha* \\ Department of Plant Medicine, Chungbuk National University, Cheongju 361-763, Korea \\ (Received on February 14, 2012; Revised on April 29, 2012; Accepted on May 2, 2012)
}

Periwinkle seedlings (Cantharanthus roseus) were inoculated with jujube witches'- broom (JWB) phytoplasma via grafting to analyze the migration of JWB phytoplasmas within the host plant. The phytoplasmas were detected using nested polymerase chain reaction (PCR) and fluorescence microscopy. Fluorescence microscopy was a simple and easy method of detecting phytoplasmas; however, it was not sufficiently sensitive to detect very low phytoplasma concentrations. Therefore, the migration of JWB phytoplasma was investigated through PCR. The first migration of JWB phytoplasma from an infected tissue to healthy tissues occurred late. After grafting, the phytoplasmas moved from the inoculated twig (or scion) to the main stem, which took 28 days. Afterward, the phytoplasma migrated faster and took less than 4 days to spread into the roots from the main stem. All twigs were then successively colonized by the JWB phytoplasmas from the bottom to the top. JWB phytoplasma was detected via nested PCR in all parts of the periwinkle seedling 82 days after inoculation. Based on these results, the inoculated JWB phytoplasma appeared to migrate downward to the roots along the main stem during the early stages, and then continued to move upward, colonizing twigs along the way until they reached the apex.

Keywords : grafting, migration, nested PCR, periwinkle, phytoplasma

Among the diseases of jujube (Zizyphus jujube Mill.) trees, the jujube witches'-broom (JWB) disease is the most serious and destructive. JWB is a systemic disease, with the infected trees showing typical symptoms of phytoplasmas such as witches'-broom, phyllody, and yellows. The pathogen, Candidatus Phytoplasma ziziphi, is usually present in high density in plant tissues with or without visible external symptoms, even though it is limited to the sieve elements of the plant (Jung et al., 2003; Kuske and Kirkpatrick, 1992;

\footnotetext{
*Corresponding author.

Phone) +82-43-261-2557, FAX) +82-43-271-4414

E-mail)bjcha@cbnu.ac.kr
}

Nakashima and Hayashi, 1995). However, phytoplasma is sometimes difficult to detect even in tissues that display distinct external symptoms. For example, phytoplasma cells were observed via transmission electron microscopy (TEM) in young inflorescences of coconut palms, but not in mature inflorescences, leaves, or stems with symptoms of the lethal yellows disease (Parthasarathy, 1974). This observation may indicate the involvement of phytoplasmaproduced or phytoplasma-induced substances in symptom expression. The metabolism of infected plants is known to be disturbed by phytoplasmas, resulting in the degeneration of infected sieve elements (Credi, 1994; Douglas, 1993).

Phytoplasmas are obligate endoparasites of plant cells and cannot be mechanically transmitted, thereby the study of their biological and phytopathological characteristics have been hindered (Kirkpatrick, 1992; McCoy et al., 1989) for a long time. After the discovery of phytoplasma as a plant pathogen, most studies focused on new diseases, including the means of transmission and disease control. Due to the fastidious nature of phytoplasmas, their distribution in the organs of an individual plant has not yet been well elucidated, even though they can be detected from the phloem sieve tubes of an infected plant. Fortunately, the progress of molecular biological techniques such as polymerase chain reaction (PCR) has made the detection of relatively low concentrations of phytoplasmas possible even in plants with extremely mild symptoms or asymptomatic (Ahrens and Seemüller, 1992; Christensen et al., 2004; Garcia-Chapa, 2003; Lee et al., 1995).

Several studies on the localization and migration of phytoplasmas within infected plant tissues have been conducted (Cha and Tattar, 1991; Seemüller et al., 1984; Yi et al., 2001). About a decade ago, Wei et al. (2000) verified that mulberry dwarf phytoplasma is distributed to an entire vein and petiole of a mulberry leaf by using nested PCR. A dynamic analysis of onion yellows phytoplasmas in Chrysanthemum coronarium was also conducted (Wei et al., 2004). However, little is still known on the distribution and migration of phytoplasmas in plant organs, including roots, buds, flowers, and fruits. Hence, findings on the withinplant distribution of phytoplasmas and their migration from 
the inoculated tissue to the rest of the plant are very important in understanding their ecology and developing effective control strategies.

Therefore, to analyze the migration and distribution of phytoplasmas within a plant, twig cuttings (scions) of JWBinfected periwinkles (Cantharanthus roseus) were graftinoculated onto the stem of healthy periwinkles in this study, and the JWB phytoplasmas within the plant was investigated via PCR and fluorescence microscopy.

Periwinkles inoculated with JWB phytoplasma using an insect vector, Hishimonus sellatus, and exhibiting witches'broom and phyllody symptoms were used as inoculum sources for this research. The scions were obtained from these plants and grafted onto the stems of healthy periwinkles. These rootstocks were raised from seeds and were almost of the same age. They were planted each in a plastic pot and then trimmed, particularly the topping of the apical shoot, to a similar shape when their height reached approximately $10 \mathrm{~cm}$ (Fig. 1). Throughout the experiment, all periwinkles were kept in a net cage in a greenhouse under the controlled temperature $\left(16-35^{\circ} \mathrm{C}\right)$.

For JWB phytoplasma inoculation, approximately $3 \mathrm{~cm}$ long scions were taken from $3 \mathrm{~mm}$ to $4 \mathrm{~mm}$ thick symptomatic twigs, with the leaves and minor twigs trimmed. Each

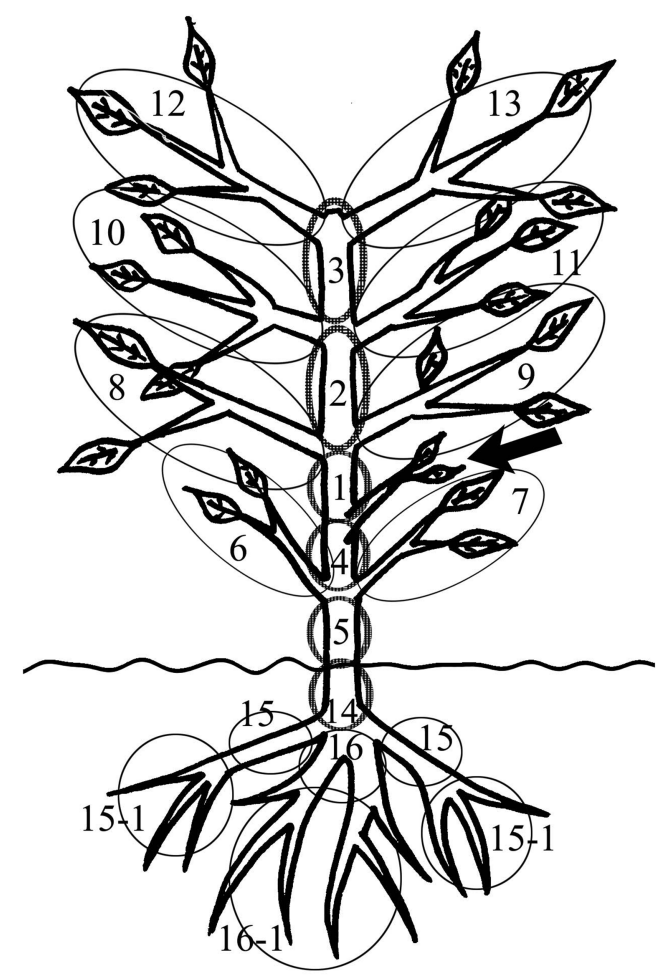

Fig. 1. Segmentation of periwinkles (Catharanthus roseus) graftinoculated with jujube witches'-broom phytoplasma for the investigation of its migration and distribution. The circles and numbers indicate the sampling sites, and the arrow indicates the grafted scion. scion was grafted onto the third node of the stem of each healthy periwinkle (Fig. 2). A total of 250 periwinkle seedlings were inoculated via grafting with the scions of JWB phytoplasma-infected periwinkles. The seedlings were grown for a year from one-year old twigs and the scions were prepared from this year's twigs. Five periwinkle seedlings were then randomly collected every other day to monitor the migration of the phytoplasma from the grafting point to other plant parts.

Periwinkle seedlings inoculated with JWB-infected scions were randomly collected, and each seedling was segmented into 18 parts, including the roots (Fig. 1). All segments were subjected to fluorescence microscopy and PCR to confirm the presence of phytoplasmas.

For fluorescence microscopy, less than $0.1 \mathrm{~mm}$ thick cross- or longitudinal sections were prepared from each segment of a periwinkle seedling via hand sectioning using a razor blade. Five sections were obtained from each segment. The sections were stained with 1,000 ppm of 4',6'diamidino-2-phenylindole (DAPI) for $10 \mathrm{~min}$ (Cha and Tattar, 1991) prior to examination under a fluorescence

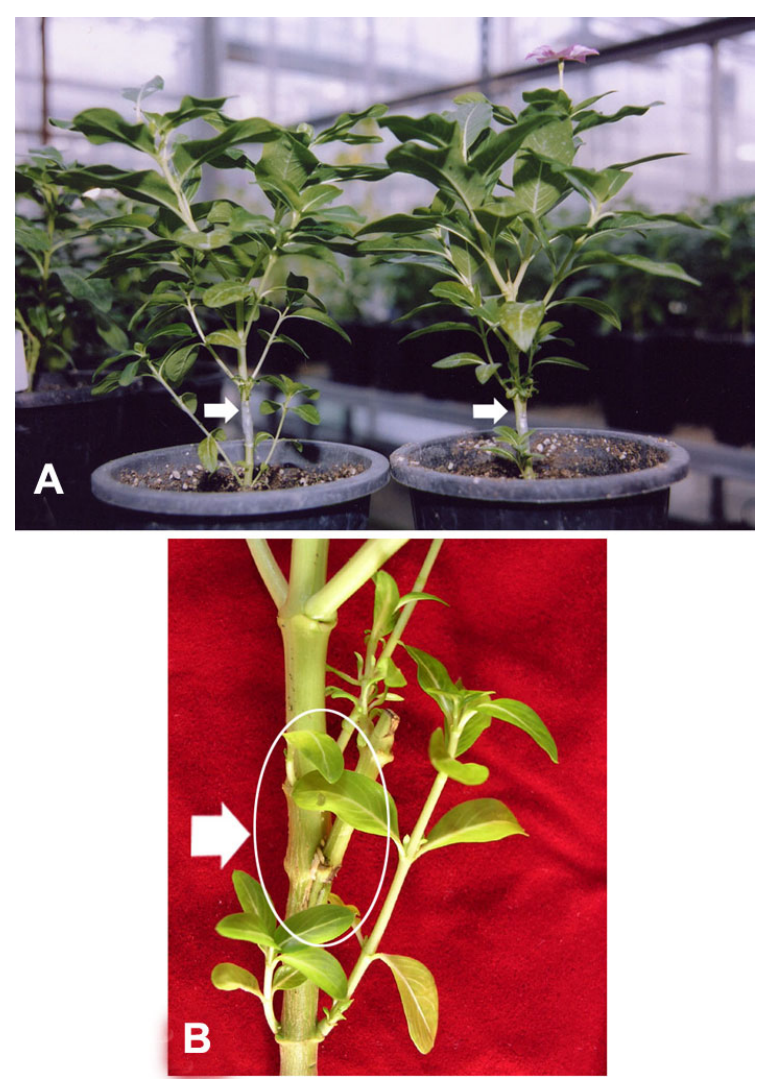

Fig. 2. Inoculation of jujube witches'-broom phytoplasma to healthy periwinkles (Cantharanthus roseus) via grafting with the scion of an infected periwinkle (A) and close up of the grafting site (B). The white arrows and the circle indicate the grafting sites on the main stems, respectively. 
microscope (BX50, Olympus Optical, Tokyo, Japan).

For PCR, total DNA was extracted from each organ of each segment following the procedure of Namba et al. (1993), with some modifications (Fig. 1). The tissues used in total DNA extraction were the leaf midrib and petiole, phloem tissues under the bark of twigs, and phloem tissues inside the root endodermis. Phytoplasmal DNA was detected using the universal primer pair AS-1/AS-2 of Ahrens and Seemüller (1992). Direct PCR amplification also followed Ahrens and Seemüller (1992), with minor modifications, using a gene cycler (T-Personal $48^{\mathrm{TM}}$, Biometra, Göttingen, Germany). Amplification was performed via denaturation for $10 \mathrm{~min}$ at $95^{\circ} \mathrm{C}$, denaturation for $1 \mathrm{~min}$ at $94^{\circ} \mathrm{C}$, annealing for $2 \mathrm{~min}$ at $58^{\circ} \mathrm{C}$, and then an extension for $3 \mathrm{~min}$ at $72^{\circ} \mathrm{C}$. This cycle was replicated 30 times, with a final extension at $72^{\circ} \mathrm{C}$ for $10 \mathrm{~min}$.

Phytoplasmal DNA samples not amplified in direct PCR were analyzed using nested PCR. In nested PCR, the universal primer pair SN910601/SN910502 (Namba et al., 1993) was used for the first amplification, and the other universal primer pair, AS-1/AS-2 (Ahrens and Seemüller, 1992), was used for the second amplification. The direct PCR product was used as template DNA in the second amplification. The first amplification was performed for 30 cycles under the following conditions: denaturation at $95^{\circ} \mathrm{C}$ for $10 \mathrm{~min}$ and at $94^{\circ} \mathrm{C}$ for $1 \mathrm{~min}$, annealing at $60^{\circ} \mathrm{C}$ for 2 min, and an extension at $72^{\circ} \mathrm{C}$ for $3 \mathrm{~min}(10 \mathrm{~min}$ in the final cycle). The reaction condition for the second amplification was identical to that of direct PCR, except for the 24-cycle replication. The final PCR products were then analyzed through electrophoresis on $1.5 \%$ agarose gel $(0.5 \times \mathrm{TBE})$ and staining with ethidium bromide (final concentration, 50 $\mathrm{ng} / \mathrm{ml}$ ) for $30 \mathrm{~min}$. After $10 \mathrm{~min}$ of destaining in distilled water, DNA amplification was performed under a UV transilluminator.

Both fluorescence microscopy and PCR could detect the migration of phytoplasma in a periwinkle plant prior to external symptom expression. Phloem sieve tubes colonized by phytoplasma and stained with DAPI showed bright, pale blue fluorescence under the fluorescence microscope (Fig. 3) and presented a phytoplasma-specific band in PCR (Fig. 4). However, the detection sensitivity of PCR was significantly higher than that of fluorescence microscopy.

No phytoplasma in any part of the periwinkle was detected with either fluorescence microscopy or PCR until 26 days after graft-inoculation of the phytoplasma-infected scion; phytoplasma was detected only in the scion itself. Phytoplasma migration was first detected in segments other than scion 28 days after grafting (Fig. 5). Phytoplasma first moved downward through the main stem from the grafting site. The PCR results of segment 5 showed a phytoplasmaspecific band; however, no phytoplasma was detected via
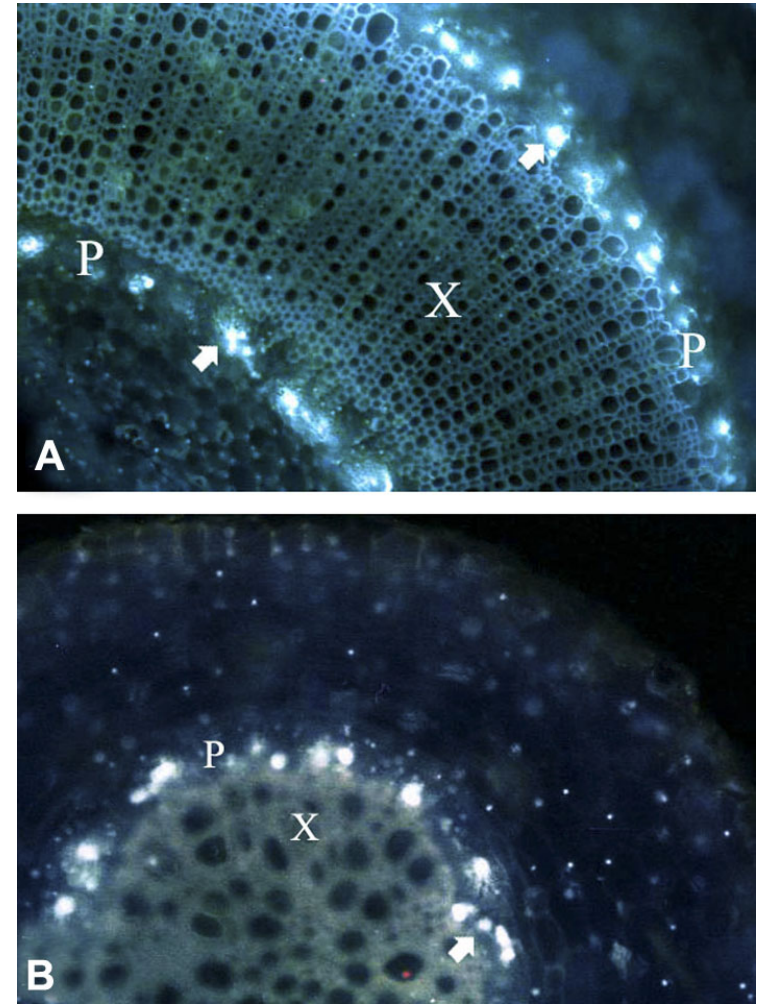

Fig. 3. Fluorescence microscopy of the cross-section of jujube witches'-broom phytoplasma-infected twig (left) and root (right) of Catharanthus roseus stained with 4',6'-diamidino-2-phenylindole (DAPI). The arrows indicate the phytoplasma-specific DAPI fluorescence in the phloem. P: phloem, X: xylem.

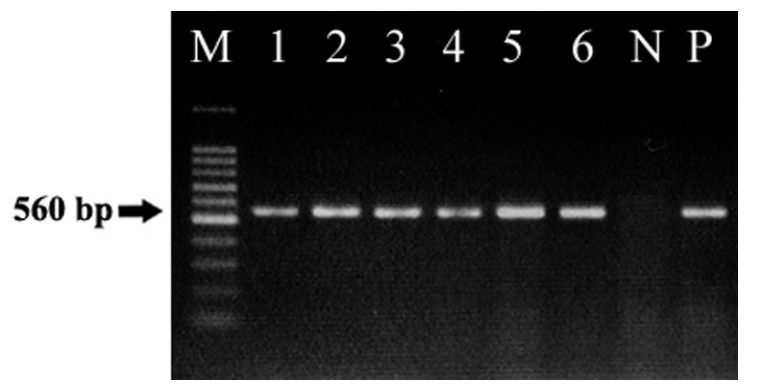

Fig. 4. PCR detection of jujube witches'-broom (JWB) phytoplasma from periwinkles (Cantharanthus roseus) inoculated via grafting. M: $100 \mathrm{bp}$ DNA ladder; lanes 1 and 2: root samples; lanes 3 and 4: mid-vein samples; lanes 5 and 6: twig samples; N: healthy plant tissue; $\mathrm{P}$ : twig samples of JWB infected jujube tree.

fluorescence microscopy. After two days, PCR detected phytoplasmas in segments 4 and 5. At 32 days after grafting, phytoplasma was detected in the main root and underground parts (segments 14 and 16). On the 34th day, phytoplasma was distributed in all segments under the grafting site. However, two twigs between the grafting site and the soil-line, namely, segments 6 and 7, did not show any evidence of phytoplasmal colonization. From then on up to 

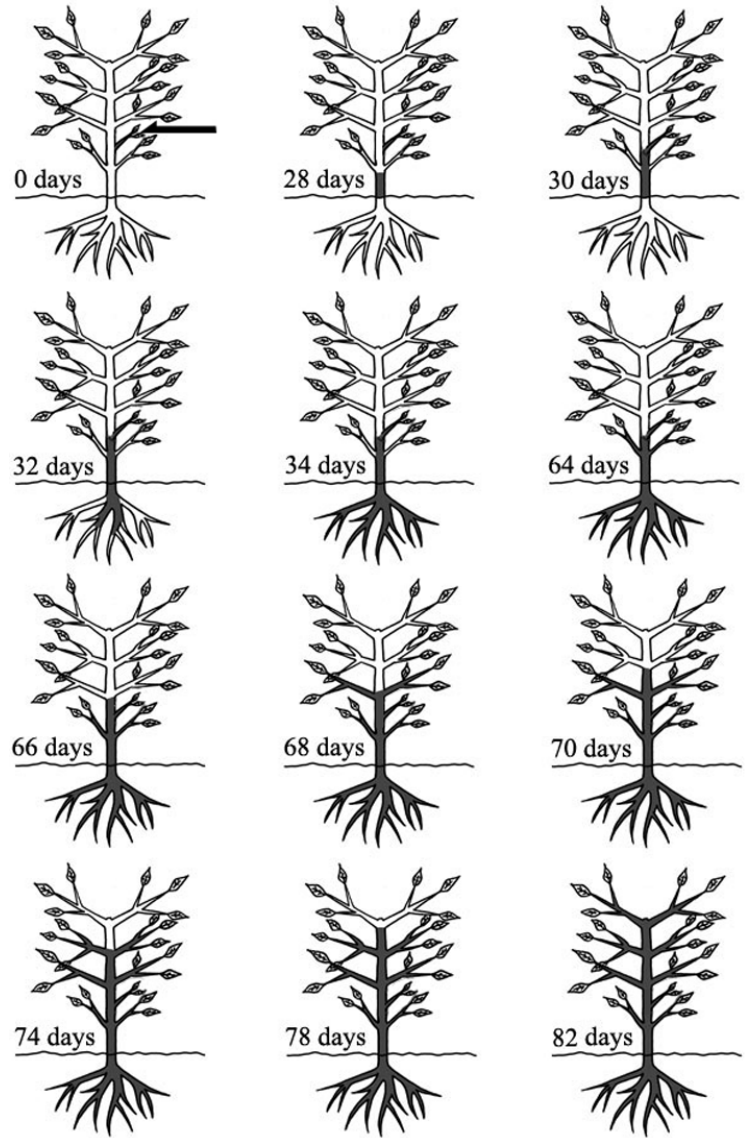

Fig. 5. Migration and distribution of jujube witches'-broom phytoplasma within the graft-inoculated Cantharanthus roseus. The dark gray areas represent phytoplasma detection. A black arrow on ' 0 day' indicates the scion for phytoplasma inoculation.

the $62^{\text {nd }}$ day, phytoplasma was not detected on any other part of the periwinkle except for the segments that already showed its presence.

Phytoplasma migration was again detected 64 days after grafting. Segments 6 and 7 showed phytoplasma-specific bands in PCR. On the $66^{\text {th }}$ day, phytoplasma was detected in segment 1 and was the first evidence of phytoplasmal colonization above the grafting site. Afterward, phytoplasma continued to migrate upward, and subsequent colonization was observed in segments 8 and 9 on the $68^{\text {th }}$ day, and in segment 2 on the $70^{\text {th }}$ day.

On the other hand, the first detection of phytoplasmaspecific DAPI fluorescence (Fig. 3) in the phloem was observed 64 days after grafting in segments 5 and 14 , as well as in the root tissues; however, the fluorescence of these segments was paler and dimmer than that of the scion. Segments 6 and 7 showed DAPI fluorescence on the 70th day, i.e. 6 days after the first detection via PCR.

External symptoms first appeared on the twigs of segments 6 and 7 on the $72^{\text {nd }}$ day. On the $81^{\text {st }}$ day, the twigs on

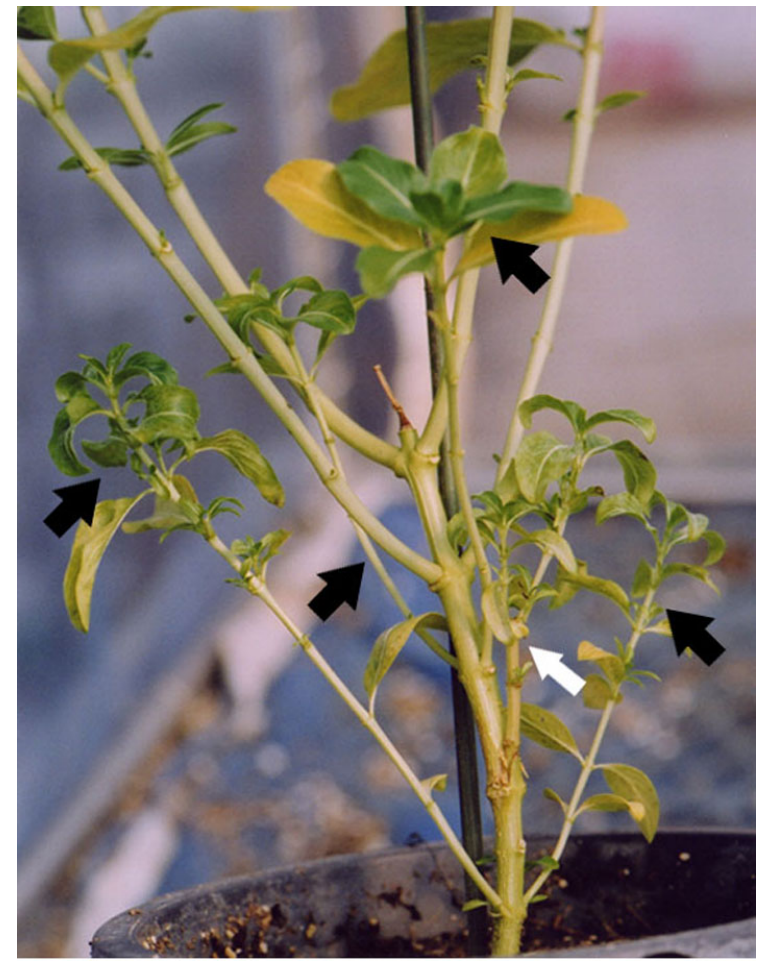

Fig. 6. Early symptoms (black arrows) on Cantharanthus roseus inoculated with jujube witches'-broom phytoplasma via grafting (small white arrow).

segments 8 and 9 also showed visible phytoplasma symptoms (Fig. 6).

On the $82^{\text {nd }}$ day, phytoplasma was detected via PCR in all periwinkle segments. However, no phytoplasma in segments 8 and 9 , as well as in segments below them (where visible symptoms appeared), were detected via fluorescence microscopy.

Very little is known on the migration and translocation of phytoplasmas in plants because they cannot be inoculated mechanically. Among the very few inoculation methods, grafting was used in this research to obtain uniform inoculations. The detection of phytoplasma translocation in the periwinkle plant via PCR occurred much earlier than that via fluorescence microscopy. Generally, fluorescence microscopy is capable of detecting the colonization of phytoplasmas in plant tissues ahead of the appearance of visible symptoms. However, it sometimes provides falsenegative results (Seemüller, 1976), especially when the density of phytoplasma is not sufficiently high. By contrast, PCR can detect very low phytoplasma densities even in asymptomatic tissues. In this research, strong phytoplasmaspecific DAPI fluorescence was observed mostly from the phloem sieve tubes of the symptomatic twigs, whereas PCR detected phytoplasmas of relatively low density. PCR confirmed the presence of phytoplasma in the tissue 36 
days earlier than fluorescence microscopy, indicating that the density of phytoplasma was not high enough to be detected by fluorescence microscopy during the early stages of infection and migration. Therefore, migration of JWB phytoplasma in the periwinkle plant was investigated based on the PCR results.

Amplification of phytoplasmal DNA was first detected from the main stem segment right below the grafting site 28 days after grafting. It was proved that phytoplasmas in the scion first moved to the main stem, where the scion was grafted. The phytoplasma then migrated downward from the grafting site through phloem sieve tubes (Jiang et al., 2004; Seemüller, 1988). Initially, JWB phytoplasmas were thought to migrate too slowly and were not detected from any other part except in the scion 26 days after grafting, possibly because the time needed for the fusion of grafted plant tissues (usually ranging from several days to more than 10 days) and the multiplication of the phytoplasmas delayed their migration during this period. Migration of phytoplasmas and symptom development occurred later than usual in this research compared to the reports of Wei et al. (2004) and Saracco et al. (2006). This phenomenon may be due to environmental conditions as well as the inoculation method used in this study. Generally, more days are needed for symptom development in graft inoculations compared with that of insect-vector or dodder-bridge inoculation (Nakashima and Hayashi, 1995; Wei et al., 2000).

Therefore, if all conditions are favorable for plant grafting and phytoplasma multiplication, the time needed for their migration will be shorter than the results obtained in this research.

Upon reaching the main stem, the phytoplasmas moved relatively faster and took only four days to reach the roots. JWB phytoplasma was distributed to all the roots within two days after its first invasion of the root tissues. During this period, the phytoplasmas only moved downward, and the twigs above the grafting site remained free of colonization. More than two months passed before the twigs showed the presence of phytoplasma in their phloem, as detected through nested PCR.

After colonizing the roots, the phytoplasmas appeared to stay in the tissues already colonized and did not migrate to any other part of the plant for one month. This result suggests that the phytoplasmas multiplied in the roots to some extent and then moved upward (Siddique, 1998). All twigs were colonized by JWB phytoplasmas in succession, from the bottom to the top. JWB phytoplasma was detected via nested PCR in every segment of the periwinkle seedling 82 days after inoculation, colonizing the entire plantlet.

The plants were approximately $15 \mathrm{~cm}$ tall at the beginning of the experiment, but grew to about $40 \mathrm{~cm}$ in height at the end of the experiment and retained the same shape.

Based on these results, it is evident that the inoculated JWB phytoplasma seems to migrate downward to the roots along the main stem during the early stages. Once they infect the roots, the phytoplasmas multiply without migrating. The phytoplasmas then continue moving upward and colonize the twigs along the stem until they reach the apex. In other words, JWB phytoplasmas infect the twigs on the main stem in succession, from the bottom to the top. However, some reports provided migration results that differed with those obtained in this research. In the experiment wherein onion yellows phytoplasma was inoculated on Chrysanthemum coronarium via an insect vector, the phytoplasma moved both upward and downward from the inoculated leaf, and the main stem and twigs were successively infected from the top to the bottom (Wei et al., 2004). When flavescence doree phytoplasma was inoculated on Vicia faba and examined with ELISA and immunocytochemistry, phytoplasma was first detected from the roots 17 days after inoculation (Lherminier et al., 1994). Wei et al. (2004) reported results that are very similar to migration of viruses in plants but different from the results of the current research. However, different from plant viruses, the presence or colonization of any phytoplasma in plant tissues other than the phloem has not yet been reported. Therefore, phytoplasmas possibly pass through the phloem sieve tubes when they migrate upward. In this case, the upward migration of phytoplasmas should be slow because they go against the phloem stream. Therefore, discovering which tissue serves the migration of phytoplasmas is highly important. The differences among the various studies can be attributed to the differences in the sensitivity of the detection tools, as well as the different host species, host plant growth conditions, and the interaction of host and phytoplasma.

\section{Acknowledgement}

This work was supported by the research grant of the Chungbuk National University in 2009.

\section{References}

Ahrens, U. and Seemüller, E. 1992. Detection of DNA of plant pathogenic mycoplasmalike organisms by polymerase chain reaction that amplifies a sequence of the $16 \mathrm{~S}$ rRNA gene. Phytopathology 82:828-832.

Cha, B. and Tattar, T. A. 1991. Symptom development of ash yellows and fluctuation of mycoplasma-like organism population in white ash (Fraxinus Americana L.). Arboricultural $J$. 15:323-343.

Christensen, N. M., Nicolaisen, M., Hansen, M. and Schulz, A. 
2004. Distribution of phytoplasmas in infected plants as revealed by real-time PCR and bioimaging. Mol. PlantMicrobe Interact. 17:1175-1184.

Credi, R. 1994. Occurrence of anomalous mycoplasma-like organisms in grapevine yellows-diseased phloem. J. Phytopathol. 142:310-316.

Douglas, S. M. 1993. Cytology, histology, and histochemistry of MLO infections in tree fruits. In: Handbook of Cytology, Histology, and Histochemistry, ed. by A. R. Biggs, pp. 253-279. CRC Press, Inc., Boca Raton, FL

Garcia-Chapa, M., Medina, V., Viruel, M. A., Laviña, A. and Batlle, A. 2003. Seasonal detection of pear decline phytoplasma by nested-PCR in different pear cultivars. Plant Pathol. 52:513-520.

Jiang, H., Wei, W., Saiki, T., Kawakita, H., Watanabe, K. and Sato, M. 2004. Distribution patterns of mulberry dwarf phytoplasma in reproductive organs, winter buds, and roots of mulberry trees. J. Gen. Plant Pathol. 70:168-173.

Jung, H.-Y., Sawayanagi, T., Kakizawa, S., Nishigawa, H., Wei, W., Oshima, K., Miyata, S., Ugaki, M., Hibi, T. and Namba, S. 2003. 'Candidatus Phytoplasma zizphi', a novel phytoplasma taxon associated with jujube witches'-broom disease, Int. J. Syst. Evol. Microbiol. 53:1037-1041.

Kirkpatrick, B. C. 1992. Mycoplasma-like organisms: Plant and invertebrate pathogens. In: The Prokaryotes. 2nd ed, by A. Balows, H. G. Truper, M. Dworkin, W. Harder and K. H. Schleifer, pp. 4050-4067. Springer-Verlag, New York.

Kuske, C. R. and Kirkpatrick, B. C. 1992. Distribution and multiplication of western aster yellows mycoplasma-like organisms in Catharanthus roseus was determined by DNA hybridization analysis. Phytopathology 82:457-462.

Lee, I.-M., Bertaccini, A., Vibio, M. and Gundersen, D. E. 1995. Detection of multiple phytoplasmas in perennial fruit trees with decline symptoms in Italy. Phytopathology 85:72-735.

Lherminier, J., Courtois, M. and Caudwell, A. 1994. Determination of the distribution and multiplication sites of flavescence dorée mycoplasma-like organisms in the host plant Vicia faba by ELISA and Immunocytochemistry. Physiol. Mol. Plant Pathol. 45:125-138.

McCoy, R. E., Caudwell, A., Chang, C. J., Chen, T. A., Chiykowski, L. N., Cousin, M. T., Dale De Leeuw, G. T. N., Golino, D. A., Hackett, K. J., Kirkpatrick, B. C., Marwitz, R., Petzold, H., Sinha, R. H., Sugiura, M., Whitcomb, R. F., Yang, I. L., Zhu, B. M. and Seemüller, E. 1989. Plant disease associated with mycoplasma-like organisms. In: The Mycoplasmas, vol. 5, ed. by R. F. Whitcomb and J. G. Tully, pp. 546-640.
Academic Press, New York.

Nakashima, K. and Hayashi, T. 1995. Multiplication and distribution of rice yellow dwarf phytoplasma in infected tissues of rice and green rice leafhopper Nephotettix cincticeps. Ann. Phytopathol. Soc. Jpn. 61:451-455.

Namba, S., Kato, S., Iwanami, S., Oyaizu, H., Shiozawa, H. and Tsuchizaki, T. 1993. Detection and differentiation of plantpathogenic mycoplasmalike organisms using polymerase chain reaction. Phytopathology 83:786-791.

Parthasarathy, M. V. 1974. Mycoplasmalike organisms associated with lethal yellowing disease of palms. Phytopathology 64:667-674.

Saracco, P., Bosco, D., Veratti, F. and Marzachi, C. 2006. Quantification over time of chrysanthemum yellows phytoplasma (16Sr-I) in leaves and roots of the host plant Chrysanthemum carinatum (Schousboe) following inoculation with its insect vector. Physiol. Mol. Plant Pathol. 67:212-219.

Seemüller, E. 1976. Investigations to demonstrate mycoplasmalike organisms in diseased plants by fluorescence microscopy. Acta Horticulture 67:109-112.

Seemüller, E. 1988. Colonization patterns of mycoplasmalike organisms in trees affected by apple proliferation and pear decline. In: Tree mycoplasmas and mycoplasma disease, ed. by C. Hiruki, pp 179-192. The Univ. of Alberta Press, Canada.

Seemüller, E., Schaper, U. and Zimbelmann, F. 1984. Seasonal variation in the colonization patterns of mycoplasmalike organisms associated with apple proliferation and pear decline. Z. Pflanzenkrankh. Pflzenschutz 91:525-532.

Siddique, A. B. M., Guthrie, J. N., Walsh, K. B., White, D. T. and Scott, P. T. 1998. Histopathology and within-plant distribution of the phytoplasma associated with Australian papaya dieback. Plant Dis. 82:1112-1120.

Wei., W., Kawakita, H. and Sato, M. 2000. Detection of small population mulberry dwarf (MD)-phytoplasmas in symptomless-mulberry trees by nested PCR. J. Seric. Sci. Jpn. 69:261269.

Wei, W., Kakizawa, S., Suzuki, S., Jung, H. Y., Nishigawa, H., Miyata, S., Oshima, K., Ugaki, M., Hibi, T. and Namba, S. 2004. In planta dynamic analysis of onion yellows phytoplasma using localized inoculation by insect transmission. Phytopathology 94:244-250.

Yi, J. C., Lim, T. H. and Cha, B. 2001. Changes in phytoplasma densities in witches'-broom infected jujube trees over seasons. Kor. J. Plant Pathol. 17:295-299. 